\title{
Frequency Distribution of Hepatitis C Virus Genotypes with Reference to Age and Sex in Various Districts of Khyber Pakhtunkhwa, Pakistan
}

\author{
Authors: \\ Bakht Biland, ${ }^{1}$ Mohsina Haq, ${ }^{1}$ Sardar Muhammad, ${ }^{1}$ Mohsan Subhani, ${ }^{2}$ \\ Syed Gardezi, ${ }^{3}$ Najibul Haq, ${ }^{*}$ Nadeem Tehami ${ }^{4}$ \\ 1. Peshawar Medical College, Pakistan \\ 2. Nottingham Digestive Disease Biomedical Research Centre, University of \\ Nottingham, UK \\ 3. The Grange University Hospital, Aneurin Bevan University, Cwmbran, UK \\ 4. University Hospital Southampton NHS Foundation Trust, UK \\ *Correspondence to nadeem.tehami@nhs.net
}

Disclosure: $\quad$ The authors have declared no conflicts of interest.

Received: $\quad 26.12 .20$

Accepted: $\quad 07.06 .21$

Keywords: $\quad$ Cross-sectional study, distribution, epidemiology, genotype, hepatitis C virus (HCV), population study.

Citation: $\quad$ EMJ Hepatol. 2021;9[1]:83-88

\section{Abstract}

Background: Pakistan has the second highest prevalence of hepatitis $C$ in the world after Egypt. Viral hepatitis is a leading cause of morbidity and mortality in Pakistan and, worryingly, reinfection rates are also on the rise. This cross-sectional study was aimed at finding the most common genotypes of hepatitis $C$ in terms of age and sex in a Pakistani cohort.

Materials and methods: The authors collected blood samples from 1,260 patients with diagnosed hepatitis $C$ visiting a primary teaching hospital affiliated with Peshawar Medical College, Pakistan, from different districts of Khyber Pakhtunkhwa, Pakistan, between January 2017 and April 2019. Hepatitis C virus RNA was quantified by real-time polymerase chain reaction and genotyping was then performed.

Results: The authors found that genotype 3a was the most prevalent type followed by 1a, mixed, and $3 b$, respectively. Genotypes $2 a$ and $1 b$ were the least prevalent in Khyber Pakhtunkhwa. The most common genotype was $3 a$, observed in $75.87 \%$ of cases. The most common mixed genotype was $3 a+1 a$, observed in 39 cases (3.10\%); it had a prevalence of $3.49 \%$ in females compared with $2.70 \%$ in males. Overall, the most common age group affected by hepatitis $C$ virus was $41-50$ years (31.35\%), followed by the 51-60 years group (24.45\%). Infection rate was comparatively low in other age groups. A significant difference was observed in the prevalence of genotype $3 a$ and $2 a$ among different districts.

Conclusion: The authors concluded that genotype $3 a$ was the most prevalent genotype and it was observed more frequently in the female population, with a median age of 45 years. 


\section{INTRODUCTION}

The goal set by the World Health Organization (WHO) to eradicate hepatitis C by 2030 is a challenge for Pakistan, given that the prevalence of the virus is near that of an epidemic; a meta-analysis published in 2018 estimated a prevalence of $6.2 \%$, which is the second highest worldwide after Egypt. ${ }^{1}$ Hepatitis C virus (HCV) is a single-stranded, enveloped RNA virus from the Flaviviridae family, genus Hepacivirus. The genome of $\mathrm{HCV}$ encodes a single polyprotein, which is processed co-translationally. The single polyprotein divides into three structural and seven non-structural polypeptides. ${ }^{2,3}$ These enclosed glycoproteins are responsible for the initial stages of infection in a host cell. ${ }^{4}$

At present, $\mathrm{HCV}$ has seven recognised genotypes and 67 subtypes. The genotypes are characterised by a discrete geographical dispersion and clinical expression; for example, genotype $1 \mathrm{~b}$ is predominant in Japan, while in the USA and Europe genotype 1a is more common. ${ }^{5}$ The genotype is also correlated to age and transmission route; for example, individuals who use intravenous drugs are mostly reported to have HCV genotypes $3 \mathrm{a}$ and $1 \mathrm{a}$, while genotype $1 \mathrm{~b}$ is common in those who acquired the virus via blood transfusion. ${ }^{6}$ It was observed that the older population in the USA mostly acquired HCV iatrogenically, thereby showing a correlation with age. The number of individuals worldwide infected with $\mathrm{HCV}$ is 120-130 million, which is approximately $3 \%$ of the world population. According to the WHO, 3-4 million individuals in Pakistan are infected with hepatitis $C$ each year, which contributes about 11 million HCV cases to the global disease burden.7,8

$\mathrm{HCV}$ infection is on a constant rise in Pakistan because of a lack of awareness, poor sterilisation techniques, reuse of contaminated and disposable syringes, and unscreened blood transfusions. $^{9}$ Due to non-specific symptoms, it is difficult to pick early HCV infection, even in individuals with high viraemia. The positive cases identified in clinical surveys are usually in individuals with chronic hepatitis $C^{10}$ Acute $\mathrm{HCV}$ infection may lead to chronicity because of delay or irregularity in treatment. The majority of chronic cases of hepatitis $C$ lead to cirrhosis and hepatocellular carcinoma." Due to poor socioeconomic circumstances, at present there is no health insurance system in Pakistan. The health department also receives a very small budget from the government and hence, the majority of patients still rely on cheap and easily available treatments, such as interferon and peginterferon. ${ }^{12}$ Until recently, direct-acting antiviral agents were extremely expensive; however, due to recent cost regulations, these therapies have become more widely available. ${ }^{13}$ Nevertheless, financial constraints still make it difficult for all of the 11 million individuals infected with $\mathrm{HCV}$ to be treated with direct-acting antiviral agents. Fortunately, the most prevalent genotype, 3a, responds effectively to the more conveniently available interferon therapy. Proper screening followed by genotyping is imperative before starting antiviral treatment as the efficacy, duration, and outcome of treatment will be dependent upon those tests..$^{14,15}$

\section{MATERIALS AND METHODS}

\section{Sample Collection}

The authors conducted a cross-sectional study at Prime Teaching Hospital, Peshawar, Pakistan, affiliated with Peshawar Medical College, where patients from almost all districts of Khyber Pakhtunkhwa attend. A total of 1,260 HCVpositive cases, 630 males and 630 females, were included in the study between January 2017 and April 2019.

\section{Virologic Examination}

A total of 1,260 HCV-positive serum samples from an equal number of males and females (630 each) were selected for viral RNA extraction. INNO-LiPA (line probe assay) HCV kit (Innogenetics N.V. [now Fujirebio Europe N.V.], Ghent, Belgium) was used for the genotyping of HCV. Two sets of HCV universal biotinylated primers were selected for the amplification of the 5' non-coding region of the HCV genome because of highly conserved base pairs. The HCV RNA-amplified products were hybridised to immobilise oligonucleotides specific for the genotypes of HCV. The HCV RNA quantification method described by Sarrazin et al. ${ }^{16}$ was used for CAP/CTM test (Roche Molecular Systems, Inc., Branchburg, New Jersey, USA). The extraction of RNA was performed by automated 
COBAS $^{\circledast}$ Ampliprep using $1 \mathrm{~mL}$ of plasma, and the extracted RNA was amplified by automated real-time polymerase chain reaction. The COBAS ${ }^{\circledR}$ TaqMan $^{\circledR} 48$ Analyzer was used for the detection of amplified RNA. Data analysis was performed using the AMPLILINK software, which presented $\mathrm{HCV}$ load as Log10 international units $/ \mathrm{mL}$. The real-time-PCR-positive samples were further subjected to genotyping assays.

\section{Statistical Analysis}

This study did not test any specific hypothesis. The continuous data were presented in percentages and descriptive statistics were outlined. The independent samples t-test and binomial test were used. A $p$ value of $<0.05$ was considered significant.

\section{RESULTS}

\section{Hepatitis C Virus Genotype Distributions in Different Age Groups}

A total of 1,260 patients were divided into seven age groups. Starting from 10 years of age, each group had a difference of 10 years and HCV genotype prevalence was recorded and analysed for each group (Figure 1). The highest prevalence of HCV was observed in the 41-50 years age group with 395 cases (31.35\%), followed by the 51-60 years age group with 308 cases (24.45\%). The lowest HCV prevalence was noted in the patients $>70$ years of age (1.43\%) and those $<20$ years of age (3.65\%). There was no significant relationship found between age and genotype $(p=0.028)$ when controlled for sex.

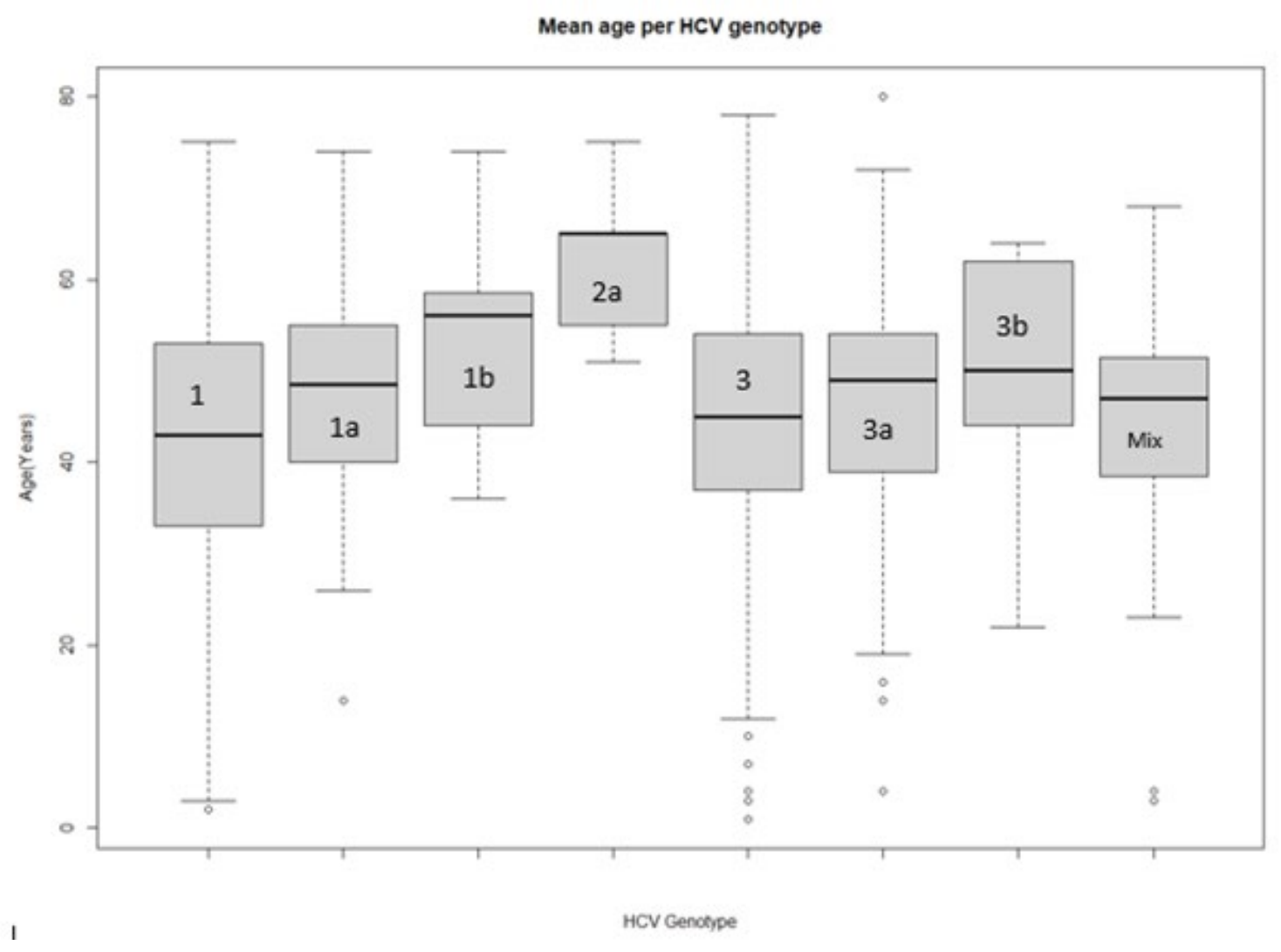

Figure 1: Box plot of distribution of mean age across hepatitis $\mathrm{C}$ virus genotypes.

HCV: hepatitis C virus.

\section{Sex-Based Hepatitis C Virus Genotype Distributions}

It was observed that the most prevalent $\mathrm{HCV}$ genotype in both sexes was $3 a$, with a total of
956 cases (75.87\%); however, the prevalence was slightly higher in females with 487 cases (77.30\%) compared to 469 cases (74.44\%) in the male population. The second most prevalent $\mathrm{HCV}$ genotype observed was 1a with 250 
isolates (19.84\%). Genotype 1a was, however, slightly more prevalent in males, with 135 isolates (21.43\%) as compared to 115 isolates in females (18.25\%). A fairly significant number (39; 3.10\%) of isolates had mixed genotypes, with a slightly higher prevalence in females: 22 cases (3.49\%) compared to 17 cases $(2.70 \%)$ in the male population. Genotypes 1b, 2a, and 3b were more common in males.

The highest number of patients from a single district of Khyber Pakhtunkhwa was 736 (58.41\%) from Peshawar, followed by Mardan with 78 cases (6.19\%), Lower Dir with 63 cases (5.00\%), and Dera Ismail Khan with 57 cases (4.52\%). The most prevalent genotype in all districts was $3 a$, with slightly differing rates of prevalence. For example, district Buner had $94.12 \% 3$ a isolates, which was the highest prevalence of genotype 3a, followed by Nowshera with 91.12\%, and Banu with 89.47\%; Swabi had comparatively low prevalence of 3 a with $57.89 \%$. The second most common genotype, 1a, had the highest prevalence in Khyber Agency with $33.34 \%$ isolates, followed by Swabi with $31.58 \%$ and Mohmand Agency with 26.09\% isolates. There were significant variations in the prevalence of HCV genotypes in the different districts of Khyber Pakhtunkhwa (Figure 2).

\section{Age- and Sex-Based Distribution of Mixed Genotypes}

A total of 39 (3.10\%) patients with mixed genotypes were observed. Genotypes $3 a+1 a$ were found in 32 patients ( $82.06 \%$ ), whereas the $3 a+2 a$ genotype was observed in three patients (7.69\%), 4a+3a in two patients (5.13\%), 3a+1b in one patient (2.56\%), and 2a-1a in one patient (2.56\%). For the mixed genotypes, 22 (56.41\%) were female and 17 (43.59\%) were male (Table 1).

\section{DISCUSSION}

It is now well established that the severity of $\mathrm{HCV}$ infection, progression, and patient response to therapy vary according to HCV genotype and subtypes. Worldwide, several regional differences appear to exist in the distribution of HCV subtypes and major genotypes.

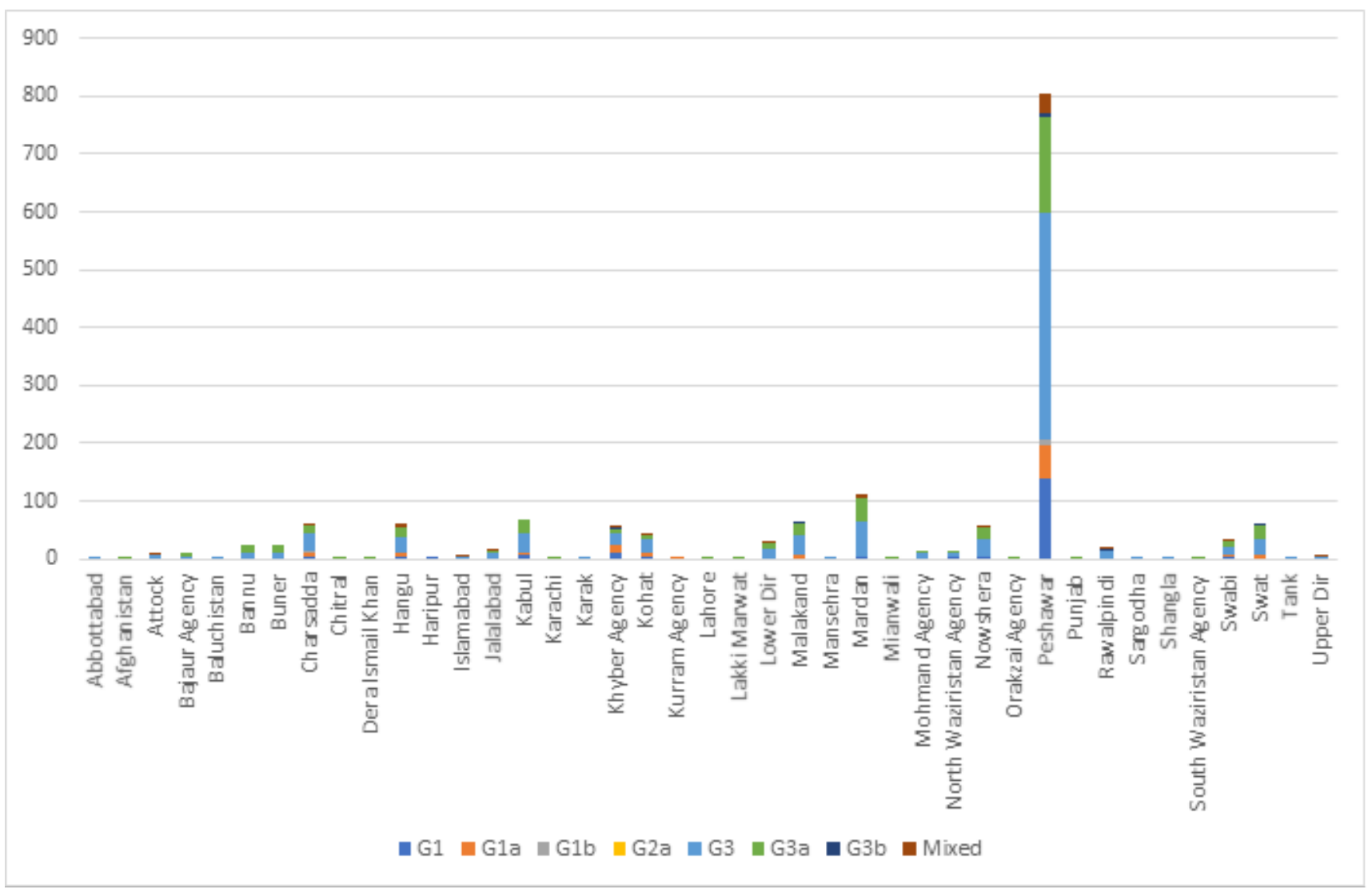

Figure 2: Balance plot of geographic distributions of hepatitis $C$ virus by genotype. 
Table 1: Mixed genotype associations with sex and age group in Khyber Pakhtunkhwa, Pakistan.

\begin{tabular}{|l|l|l|l|l|}
\hline Mixed genotype & $\begin{array}{l}\text { Age group } \\
\text { (years) }\end{array}$ & $\begin{array}{l}\text { Male } \\
\mathbf{n}(\%)\end{array}$ & $\begin{array}{l}\text { Female } \\
\mathbf{n}(\%)\end{array}$ & $\begin{array}{l}\text { Total } \\
\mathbf{n}(\%)\end{array}$ \\
\hline $2 a-1 a$ & $41-50$ & $0(0.00)$ & $1(4.55)$ & $1(2.56)$ \\
\hline $3 a-1 a$ & $29-64$ & $12(70.59)$ & $20(90.90)$ & $32(82.06)$ \\
\hline $3 a-1 b$ & $60-64$ & $1(5.88)$ & $0(0.00)$ & $1(2.56)$ \\
\hline $3 a-2 a$ & $41-64$ & $3(17.65)$ & $0(0.00)$ & $3(7.69)$ \\
\hline $4 a-3 a$ & $34-51$ & $1(5.88)$ & $1(4.55)$ & $2(5.13)$ \\
\hline Total & $\mathrm{n} / \mathrm{a}$ & $17(100.00)$ & $22(100.00)$ & $39(100.00)$ \\
\hline
\end{tabular}

n/a: not applicable.

Hence, knowledge of the distribution of the various genotypes in Pakistan is essential for the prognostic implications of chronic hepatitis $C$ infection. In this study, the authors reported genotype-based distribution of hepatitis $C$ in relation to age, sex, and geographic locality.

Although several studies have been performed on hepatitis and its genotypes in other parts of the country, a population-based data set is still lacking. It is important to note that Pakistan has the second highest prevalence of hepatitis $\mathrm{C}$ in the world next to Egypt; in the Punjab province alone, $7 \%$ of individuals are infected with $\mathrm{HCV}$ and the rate of infection is still rising. ${ }^{17-19}$

The prevalence of the various genotypes observed in the study is very similar to those reported in previous studies. A key observation in this study was the finding of the most prevalent genotype, $3 a$, followed by mixed genotypes, which was also reported by $\mathrm{Gul}$ et al. ${ }^{27}$ However, as reported previously by Idrees et al. ${ }^{26}$ in a study based in Khyber Pakhtunkhwa, no cases of genotype 5 or 6 were observed in this study. ${ }^{20-25}$ The most prevalent genotypes in the population of Khyber Pakhtunkhwa was 3a and mixed types, which was also reported by Gul et al. ${ }^{27}$ The 41-50 years age group was the most infected group, with a slight predominance in female individuals, which has also been previously reported. ${ }^{28-30}$
The frequency distribution of the HCV genotype observed in this Pakistan-based study appears to be similar to the reported genotypes from other South Asian countries such as India ${ }^{31}$ and Nepal, ${ }^{32}$ with $3 a$ as the predominant genotype; however, this pattern differs from the USA, Western Europe, ${ }^{33}$ Thailand, ${ }^{34}$ and Japan ${ }^{35}$ where the reported predominant $\mathrm{HCV}$ genotype is 1 (1a and 1b).

\section{CONCLUSION}

This study found that the most prevalent HCV genotype in Khyber Pakhtunkhwa, Pakistan, was type $3 a$ followed by 1a, mixed, 1b, 2a, and 3b. This epidemiological pattern of genotype distribution is seen across South East Asia; however, there is no agreed explanation for this observed pattern. ${ }^{20}$ It was also observed in this study that HCV genotype $3 a$ and mixed genotypes infection is slightly more common in females; on the other hand, males showed slightly higher prevalence of genotypes 1a, 1b, 2a, and 3b. The age group most affected was the 41-50 years age group, followed by the 51-60 years age group. Low prevalence was observed in individuals $>70$ years of age and $<20$ years of age. To conclude, all possible modes of HCV transmission should be communicated to the masses through awareness campaigns to control the spread of the virus. 


\section{References}

1. Al Kanaani $Z$ et al. The epidemiology of hepatitis $C$ virus in Pakistan: systematic review and meta-analyses. R Soc Open Sci. 2018;5(4):180257.

2. Grakoui A et al. Expression and identification of hepatitis $C$ virus polyprotein cleavage products. J Virol. 1993;67(3):1385-95.

3. Ali $\mathrm{N}$ et al. Hepatitis $\mathrm{C}$ virus-induced cancer stem cell-like signatures in cell culture and murine tumor xenografts. J Virol. 2011;85(23):12292-303.

4. Morozov VA, Lagaye S. Hepatitis $C$ virus: morphogenesis, infection and therapy. World J Hepatol. 2018;10(2):186-212.

5. Smith DB et al. Expanded classification of hepatitis $C$ virus into 7 genotypes and 67 subtypes: updated criteria and genotype assignment web resource. Hepatology. 2014;59(1):318-27.

6. Pawlotsky JM et al. Relationship between hepatitis $C$ virus genotypes and sources of infection in patients with chronic hepatitis C. J Infect Dis. 1995;171(6):1607-10.

7. Hanafiah KM et al. Global epidemiology of hepatitis C virus infection: new estimates of age-specific antibody to HCV seroprevalence. Hepatology. 2013;57(4):1333-42.

8. World Health Organization (WHO). Monitoring and evaluation for viral hepatitis $\mathrm{B}$ and $\mathrm{C}$ : recommended indicators and framework. 2016. Available at: https://www.who.int/ publications/i/item/monitoring-andevaluation-for-viral-hepatitis-b-andc-recommended-indicators-andframework. Last accessed: 9 June 2021.

9. Afzal MS, labal MA. Hepatitis C virus in Pakistan: community education is an effective weapon against the killer. Viral Immunol. 2017;30(8):548-51.

10. Afzal MS et al. Hepatitis C virus infection in Iran; viral spread routes in general population and safety measures. Hepat Mon. 2015;15(10):e17343.

11. Afzal MS. Hepatitis C virus and interferon-free antiviral therapeutics revolution: implications for Pakistan. Viral Immunol. 2017;30(4):252-7.
12. Raza H et al. HCV, interferon therapy response, direct acting antiviral therapy revolution and Pakistan: future perspectives. Asian Pac J Cancer Prev. 2015;16(13):5583-4.

13. Ahmad B et al. Conventional interferon therapy response among chronic HCV patients in Khyber Pakhtunkhwa. J Infect Dis Ther. 2013;1:104.

14. Afzal MS, Anjum S. Changing of HCV clade pattern in Iran; the possible means for something good. Hepat Mon. 2014;14(1):e11879.

15. Afzal MS et al. Hepatitis $C$ virus capsid protein and intracellular lipids interplay and its association with hepatic steatosis. Hepat Mon 2014;14(8):e17812.

16. Sarrazin C et al. Comparison of conventional PCR with real-time PCR and branched DNA-based assays for hepatitis $C$ virus RNA quantification and clinical significance for genotypes 1 to 5 . J Clin Microbiol. 2006:44(3):729-37.

17. Janjua N, Nizamy M. Knowledge and practices of barbers about hepatitis $B$ and $C$ transmission in Rawalpindi and Islamabad. J Pak Med Assoc. 2004:54(3):116-9.

18. Jiwani N, Gul RB. A silent storm: hepatitis C in Pakistan. J Pioneer Med Sci. 2011;1(3):89-91.

19. Arshad A, Ashfaq UA. Epidemiology of hepatitis $C$ infection in Pakistan: current estimate and major risk factors. Crit Rev Eukaryot Gene Expr. 2017;27(1):63-77

20. Attaullah $\mathrm{S}$ et al. Hepatitis $\mathrm{C}$ virus genotypes in Pakistan: a systemic review. Virol J. 2011;8:433.

21. Ali S et al. Frequency distribution of HCV genotypes among chronic hepatitis $C$ patients of Khyber Pakhtunkhwa. Virol J. 2011;8:193.

22. Afridi $S Q$ et al. Prevalence of $\mathrm{HCV}$ genotypes in district Mardan. Virol $J$. 2013;10:90.

23. Waqas $M$ et al. Distribution pattern of various genotypes of HCV circulating in district Mardan, Khyber Pakhtunkhwa, Pakistan. Advan Biol Res. 2015:9(2):69-74.

24. Tahir $M$ et al. Detection and genotyping of $\mathrm{HCV}$ in patients of Sheikh Zayed Hospital, Lahore, Pakistan. JUMDC. 2016;7(1):25-30.

25. Ilyas $M$ et al. Epidemiological study of HCV genotypes circulated in different regions of Pakistan: a lab based study. Int J Biosci. 2014;4(1):477-83.

26. Idrees M, Riazuddin S. Frequency distribution of hepatitis $C$ virus genotypes in different geographical regions of Pakistan and their possible routes of transmission. BMC infect Dis. 2008;8:69.

27. Gul A et al. New patterns of HCV subtypes distribution in the Khyber Pakhtunkhwa province of Pakistan. Braz J Infect Dis. 2016;20(1):107-8.

28. Khan $\mathrm{N}$ et al. Geographic distribution of hepatitis $C$ virus genotypes in Pakistan. Hepat Mon. 2014;14(10):e20299.

29. Wagar $M$ et al. Determination of hepatitis $C$ virus genotypes circulating in different districts of Punjab (Pakistan). Eur J Gastroenterol Hepatol. 2014;26(1):59-64.

30. Ali A et al. Determination of $\mathrm{HCV}$ genotypes and viral loads in chronic $\mathrm{HCV}$ infected patients of Hazara Pakistan. Virol J. 2011;8:466.

31. Chowdhury $A$ et al. Hepatitis $C$ virus infection in the general population: a community-based study in West Bengal, India. Hepatology. 2003;37(4):802-9.

32. Tokita $\mathrm{H}$ et al. Hepatitis $\mathrm{C}$ virus variants from Nepal with novel genotypes and their classification into the third major group. J Gen Virol. 1994;75(Pt 4):931-6.

33. Pujol FH, Loureiro CL. Replacement of hepatitis $C$ virus genotype $1 \mathrm{~b}$ by genotype 2 over a 10-year period in Venezuela. J Clin Gastroenterol. 2007;41(5):518-20.

34. Tokita $\mathrm{H}$ et al. Hepatitis $\mathrm{C}$ virus variants from Thailand classifiable into five novel genotypes in the sixth (6b), seventh (7c, 7d) and ninth (9b, 9c) major genetic groups. J Gen Virol. 1995;76(Pt 9):2329-35

35. Shinji T et al. Analysis of HCV genotypes from blood donors shows three new HCV type 6 subgroups exist in Myanmar. Acta Med Okayama. 2004;58(3):135-42. 